\title{
Evaluation of Shear Modulus of Sand Using Earthquake Records in Dynamic Centrifuge Tests
}

\author{
Segismundo, Ezequiel Q.*, Lee, Byung-Sik ${ }^{* *}$, Kim, Nam-Ryong ${ }^{\star * *}$, and Choo, Yun Wook ${ }^{* \star *}$
}

\begin{abstract}
Evaluation of the shear modulus of soil is of great importance in understanding both the fundamental soil behavior and its practical application in dynamic geotechnical problems as well as accurate analysis of seismic response of soil deposit and soil-structure interaction. There are traditionally several available techniques in measuring shear modulus of soil using laboratory tests. In this paper, calculation methods to evaluate shear modulus were reviewed from previously published works. A simple procedure was established using the previous equations. This procedure successfully obtained shear modulus of a sand deposit used for dynamic centrifuge tests. It also captured non-linear shear modulus with shear strain and effect of confining pressure. The shear modulus and normalized shear modulus versus shear strain curves from the experiment are compared with empirical curves proposed in literature. The shear modulus curves from the centrifuge tests are in reasonable agreement with the previous curves.
\end{abstract}

Key words : Shear Modulus, Sand, Dynamic Centrifuge Tests, Acceleration Records

\section{요지}

훍의 전단탄성계수 산정은 기본적인 역학적인 거동의 이해뿐 아니라, 지진시 지반의 거동 및 지반-구조물 상호작용을 이해하는데 필수 요소이다. 전통적으로 전단탄성계수는 다양한 실내실험에 의해 산정된다. 본 논문에서는 기존에 소개된 간단한 해석절차를 이용하여, 모래지반으로 수행된 동적원심모형실험에서 측정된 가속도기록으로부터 깊이별 비선형 전단탄성계수를 측정하였다. 측정된 전단탄성 계수는 모래지반의 대표적인 특성인 전단변형률에 따른 비선형특성과 구속응력의 영향을 적절하게 측정하였다. 측정된 비선형 전단탄 성계수는 기존 문헌과 비교되었고, 매우 근사하는 결과를 보였다.

핵심용어 : 전단탄성계수, 모래, 동적원심모형실험, 가속도기록

\section{Introduction}

The shear modulus $(G)$ of soils generally shows non-linear and hysteretic behavior under cyclic and dynamic loadings such as earthquake, vibration, blasting and so on (Hardin and Ricart, 1663; Richart et al., 1970; Dobry and Vucetic, 1987; Ishihara, 1996; Choo and Kim, 2005). Identification of the dynamic soil property is of great importance in the accuracy of analysis in seismic response, wave propagation problems, liquefaction problems and soil modeling programs. The variation in shear modulus with shear strain level is also used as a basic input parameter for the dynamic analysis of numerical soil modeling.

Dynamic soil properties are generally determined by per- forming laboratory element tests such as cyclic triaxial shear tests, resonant column/torsional shear tests and cyclic simple shear tests. An alternative technique in investigating dynamic soil behavior is possible with the analysis of acceleration records measured in centrifuge tests. Physical constraints of laboratory element tests can be avoided and a more realistic shear modulus of soil deposit can be measured in a direct way (Brennan et al., 2005).

It is necessary to examine the dynamic soil property with the use of available methods for model tests. In this study, those methods from previous studies were reviewed. A simple procedure was established using the previously proposed equations. The procedure was used to obtain shear modulus of a sand deposit used for dynamic centrifuge tests. Recorded time-histo-

*Member. Ms Candidate, Dept. of Civil and Environ. Eng'g., Kongju National University(E-mail: kielsegismundo@gmail.com)

**Member. Professor, Dept. of Civil and Environ. Eng'g., Kongju National University

*** Senior Researcher, Infrastructure Technology Center, K-water Institute

****Corresponding Author. Member. Associate Professor, Dept. of Civil and Environ. Eng'g., Kongju National University

(Tel: +82-41-521-9314, Fax: +82-41-568-0287, E-mail: ywchoo@kongju.ac.kr) 
ries of acceleration at different depths in centrifuge tests are utilized in determining the shear modulus of the sand model. Various peak acceleration excitations allowed the evaluation of shear moduli at different shear strain levels. The shear modulus measured in this study was then plotted with its corresponding shear strain value. Lastly, nonlinear $G$ versus shear strain curves are compared with relationships previously reported by Seed and Idriss (1970), Iwasaki and Tatsuoka (1977), and Kokusho (1980).

\section{Centrifuge Modeling}

\subsection{Centrifuge Equipment and Shaking Table}

In order to determine the degradation curve of shear modulus, dynamic centrifuge tests were performed using an uniform dry sand model. The test was conducted at the Center for Geotechnical Centrifuge Modeling at K-water research institute, Daejeon, South Korea. The platform radius of the centrifuge is $8.0 \mathrm{~m}$ and the maximum capacity is $800 \mathrm{~g}$-ton. This centrifuge (Fig. 1) is equipped with a state-of-the-art unidirectional earth-

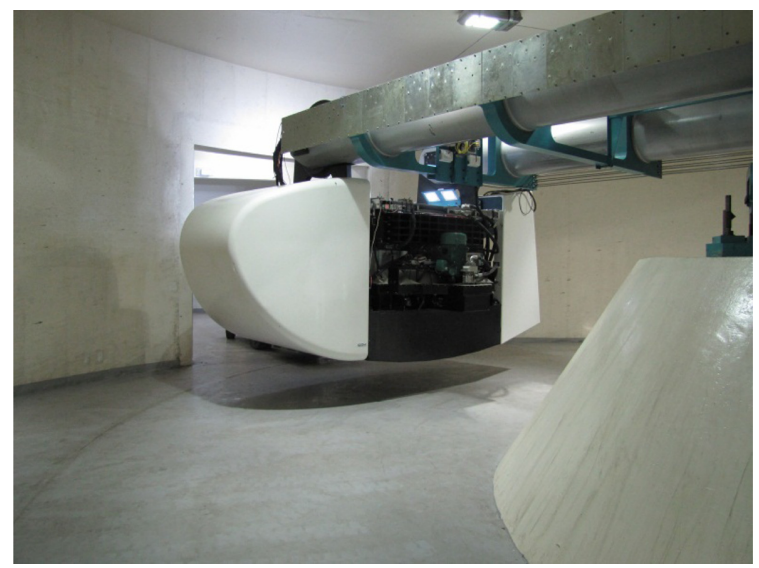

Fig. 1. Centrifuge Equipment.

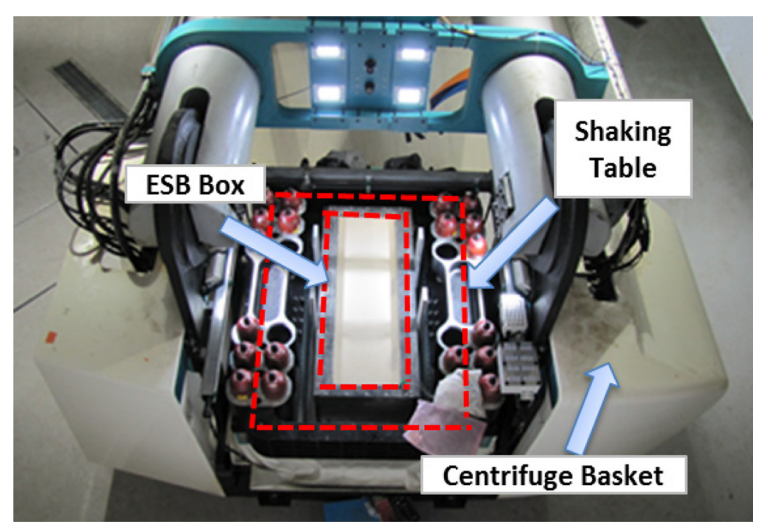

Fig. 2. Top View of Shaking Table Equipped in the Centrifuge Basket.

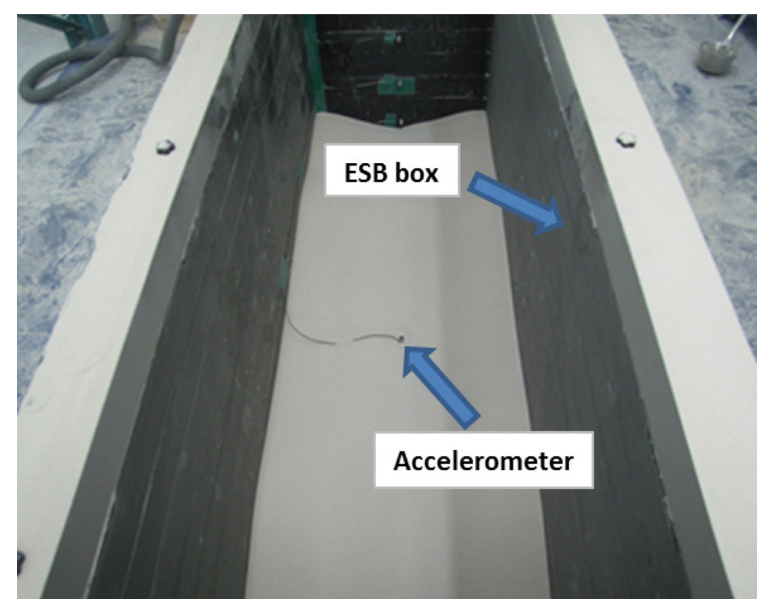

Fig. 3. Equivalent Shear Beam Box.

quake simulator/shaking table (Fig. 2) which is the largest in the world. The simulator has a platform a length of $1.8 \mathrm{~m}$ and width of $0.8 \mathrm{~m}$ and has a maximum payload capacity of 1500 $\mathrm{kg}$. It provides maximum $60 \mathrm{~g}$ horizontal shaking motion at $100 \mathrm{~g}$ centrifugal acceleration conditions and the maximum frequency of shaking motion is $300 \mathrm{~Hz}$ (Kim et al., 2014). The tests for this study were conducted using this earthquake simulator at $60 \mathrm{~g}$ centrifugal acceleration.

To solve the conflict between half-infinite boundary of in-situ soil deposit and limited boundary of a model container, an equivalent shear beam (ESB) box is used and originally proposed by Zeng and Schofield (1996). The ESB box used in this study has inner dimensions of $1.44 \mathrm{~m}$ in length, $0.44 \mathrm{~m}$ in width and $0.631 \mathrm{~m}$ in depth. One dimensional base input motion is applied on the shaking table mounted on the centrifuge. The ESB box, as shown in Fig. 3, consists of an aluminum base plate on which 10 rectangular aluminum frames were superposed. Ball bearings glued with rubber are stacked on each frame. One constant directed movement was provided by the bearing while the shearing movements with certain stiffness and sealing of the model box were provided by the rubber joints.

\subsection{Soil Material and Instrumentation}

Toyoura sand was chosen to represent soil deposit. It is classified as SP in the Unified Soil Classification System (USCS). Geotechnical properties and grain size distribution of Toyoura sand are presented in Table 1 and Fig. 4. Angle of internal friction of the sand is approximated to be $40^{\circ}$ based on Yamashita et al. (2000) friction angle range of $36-44^{\circ}$ at $100 \mathrm{kPa}$ confining pressure.

The sand mass used was prepared by an air-pluviation method at $1 \mathrm{~g}$ gravity level. The air-pluviation method is done 
Table 1. Soil Properties of the Toyoura Sand and Conditions of Soil Specimen Used in This Study

\begin{tabular}{c|c}
\hline Items & Property \\
\hline USCS & SP \\
\hline Dry density, $\rho_{d}\left(\mathrm{~kg} / \mathrm{m}^{3}\right)$ & 1568 \\
\hline Specific Gravity, $G_{s}$ & 2.679 \\
\hline Friction Angle & $40^{\circ}$ \\
\hline Void Ratio, $e$ & 0.709 \\
\hline Curvature Coefficient, $\mathrm{Cc}$ & 0.999 \\
\hline Uniformity Coefficient, $\mathrm{Cu}$ & 1.288 \\
\hline Relative Density, $D_{r(\%)}$ & 95 \\
\hline
\end{tabular}

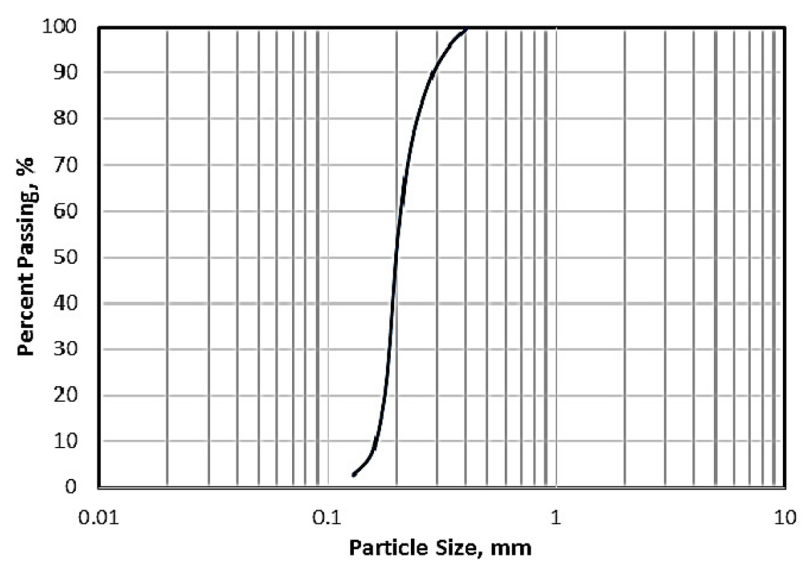

Fig. 4. Grain Size Distribution of Toyoura Sand.

by using an automatic sand rainer which is originally developed by Institut français des sciences et technologies des transports, de l'aménagement et des réseaux (IFFSTAR) in France (Garnier, 2002). Air dried sand is pluviated in the ESB container through 1-mm-diameter lined openings which is moved back and forth at a constant speed. During the air pluviation of the sand, accelerometers were buried at different depths. A vertical array of accelerometers buried in the sand deposit (see Fig. 5; A01 to A09 and A21) were used to monitor the behavior of the soil column and to measure the accelerations at these points. Fig. 5 shows the cross section of the set-up with the location of the instrumentation in the model scale.

\subsection{Input Motion Signals}

The model was subjected to earthquake-like shaking events summarized in Table 2. The peak accelerations and dominant frequencies shown in Table 2 were measured from the accelerations recorded at A21. Two excitation signals were applied and they were scaled with different peak accelerations in order to

Table 2. Input Motions in the Centrifuge Test

\begin{tabular}{c|c|c|c}
\hline \multirow{2}{*}{ Test } & \multirow{2}{*}{ Signal Type } & \multicolumn{2}{|c}{ Prototype } \\
\cline { 3 - 4 } & & $\begin{array}{c}\text { Peak Acceleration* } \\
(\mathrm{g})\end{array}$ & $\begin{array}{c}\text { Dominant Frequency } \\
(\mathrm{Hz})\end{array}$ \\
\hline 1 & Kobe (1995) & 0.038 & 3.28 \\
\hline 2 & Kobe (1995) & 0.057 & 3.33 \\
\hline 3 & Kobe (1995) & 0.084 & 1.13 \\
\hline 4 & Kobe (1995) & 0.088 & 3.32 \\
\hline 5 & Kobe (1995) & 0.119 & 2.24 \\
\hline 6 & Kobe (1995) & 0.125 & 1.12 \\
\hline 7 & Kobe (1995) & 0.129 & 1.39 \\
\hline 8 & Kobe (1995) & 0.187 & 1.12 \\
\hline 9 & Kobe (1995) & 0.207 & 1.12 \\
\hline 10 & Sine Signal & 0.148 & 1.67 \\
\hline 11 & Sine Signal & 0.234 & 1.67 \\
\hline 12 & Sine Signal & 0.243 & 1.67 \\
\hline 13 & Sine Signal & 0.253 & 1.67 \\
\hline 14 & Sine Signal & 0.361 & 1.67 \\
\hline
\end{tabular}

*Peak accelerations were measured from the A21 records.

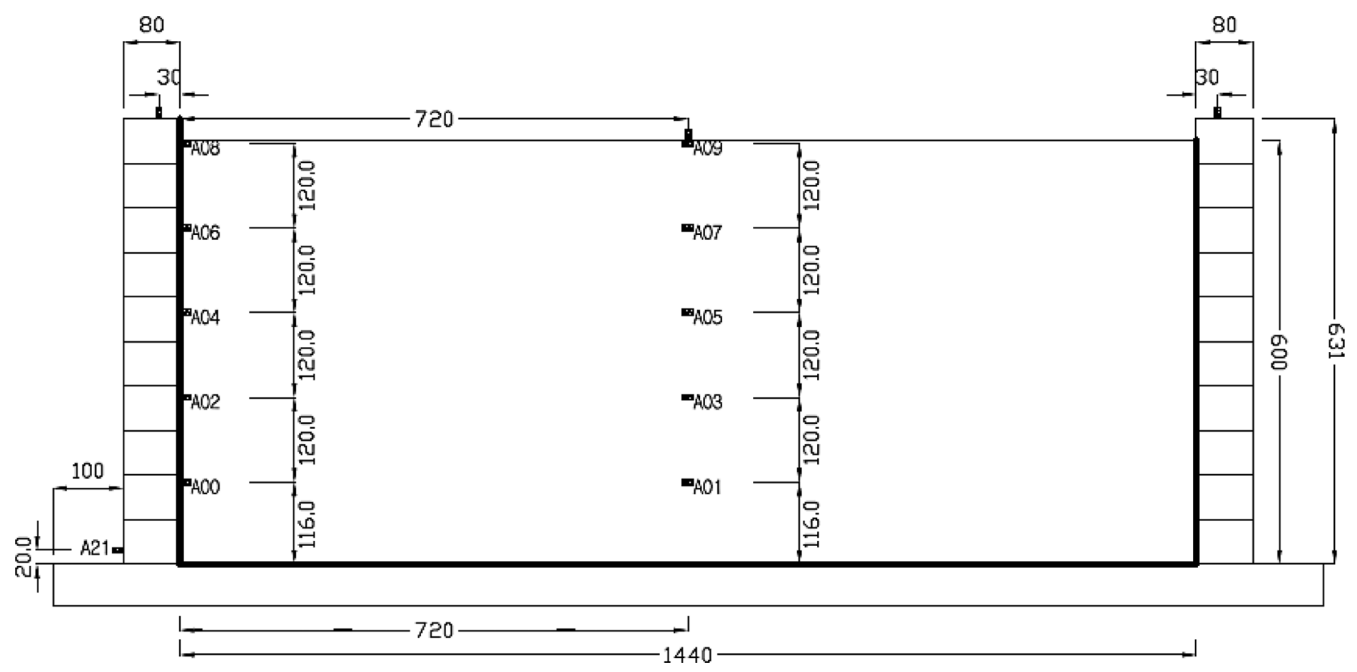

Fig. 5. Dynamic Centrifuge Test: Experiment Set-up (dimensions in mm.). 

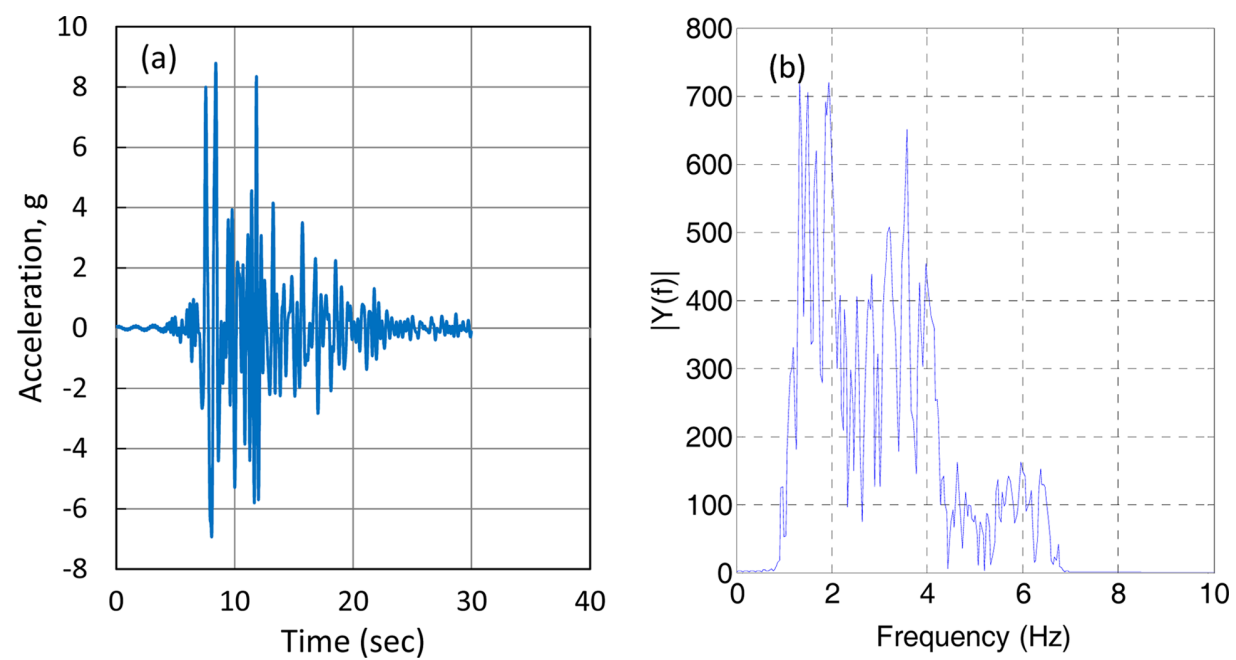

Fig. 6. (a) Input Kobe Earthquake Motion with its Corresponding (b) Frequency Content.
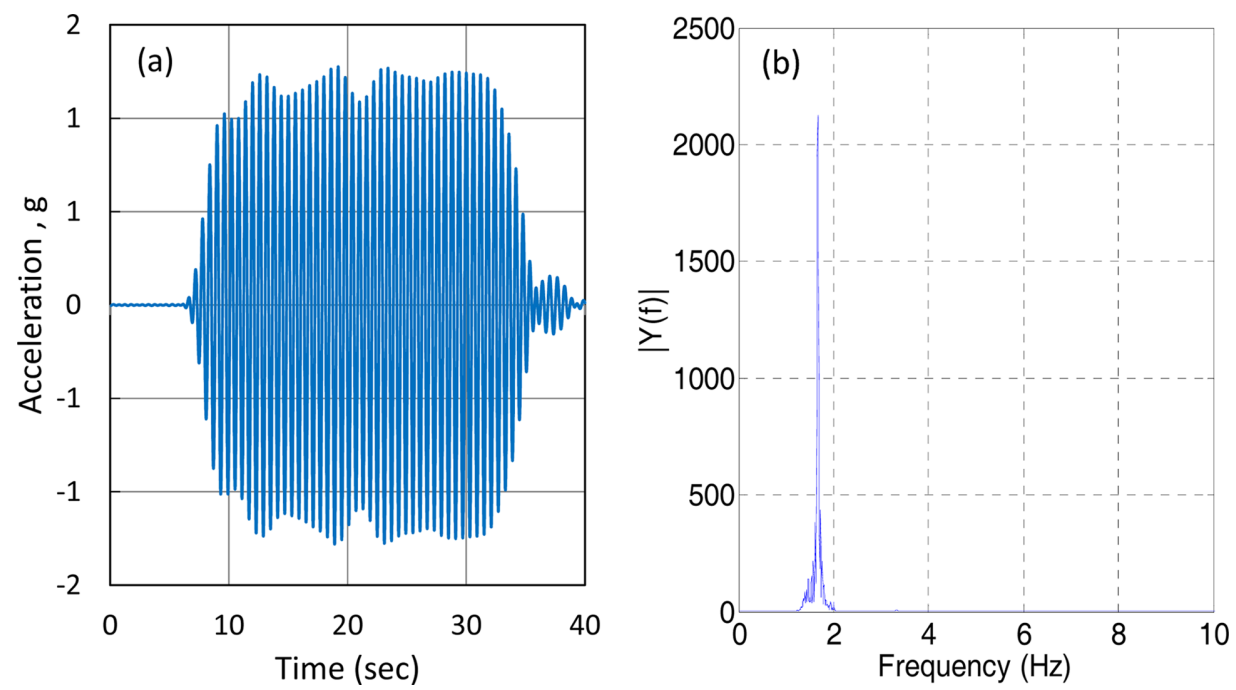

Fig. 7. (a) Input Sine Signal with its Corresponding (b) Frequency Content.

identify the shear modulus at different strain levels. One input motion is a history of the Kobe earthquake recorded in 1995 at KJMA Station 090 and it is shown in Fig. 6. The other is a sine signal (see Fig. 7) with a frequency of $100 \mathrm{~Hz}$ in model scale (equivalent to $1.67 \mathrm{~Hz}$ in prototype), which is a resonant frequency of the soil column and was estimated from another experiment carried out prior to this study. These earthquake motions were simulated at a centrifugal acceleration of $60 \mathrm{~g}$. Peak accelerations of the input motions to the soil model range from $0.038 \mathrm{~g}$ to $0.361 \mathrm{~g}$ in prototype scale.

\section{Data Filtering}

Data filtering is important in eliminating noise at high frequency and also drift errors during integration. However, over filtering of data causes distortion of the original signal and leads to wrong data interpretations. It is important to know the frequency contents of the input signal before filtering in order to appropriately tune the cut-off frequencies and to remove unwanted noise. In filtering the signal, a butterworth band-pass filters with a bandwidth between $0.5 \mathrm{~Hz}$ and $5.0 \mathrm{~Hz}$ in prototype scale $(30 \mathrm{~Hz}$ and $300 \mathrm{~Hz}$ in model scale) were employed to eliminate drifts at low frequency and noise at high frequency range. However, in this study, some displacement drifts still remains due to the limitation of band filters range.

\section{Shear Modulus}

\subsection{Literature Review of Shear Modulus}

Shear modulus of soil $(G)$ are one of important parameters in the analysis and design of soil-structure systems subjected to cyclic and dynamic loadings. The parameters affecting shear 
modulus are void ratio, confining pressure, over-consolidation ratio, geologic age, soil type, plasticity, strain amplitude and so on (Hardin and Richart, 1963; Richart et al., 1970; Dobry and Vucetic, 1987; Ishihara, 1996). Especially, the strain amplitude is considered as a key variable (Kokusho, 1980; Dobry and Vucetic, 1987; Tatsuoka and Shibuya, 1992; Choo and Kim, 2005).

Soils under dynamic loading show different behaviors depending on shearing strain amplitude, $\gamma$, at small $\left(\gamma<10^{-3} \%\right)$ to medium $\left(10^{-3} \%<\gamma<10^{-1} \%\right)$ strains. Shear modulus can be generally divided into two strain ranges. (1) At small strains below elastic threshold strain $\left(\gamma_{t h}{ }^{e}\right)$, soils exhibit linear quasielastic behavior and $G$ is constant independent of strain amplitude and called small strain shear modulus or maximum shear modulus $\left(G_{\max }\right)$. (2) At higher strains than the threshold strain, soils behave nonlinearly and shear modulus are presented in a normalized form with $G / G_{\max }$ (Drnevich and Richart, 1970; Vucetic 1994; Stokoe et al., 1994; Ishihara, 1996; Choo and Kim, 2005). The intensive investigations of shear modulus in two different regions have been carried about and published.

Studies of Hardin and Drnevich (1972b), Seed and Idriss (1970), Iwasaki and Tatsuoka (1977), and Kokusho (1980) shows that the void ratio and effective confining pressure greatly affects the $G_{\max }$ of fine grained sands. In this paper, Eq. (1), Eq. (2), and Eq. (3) which were proposed by Seed and Idriss (1970) for clean sand, Iwasaki and Tatsuoka (1977) for Toyoura sand and Kokusho (1980) also for Toyoura sand, respectively, were used in calculating the $G_{\max }$.

$$
\begin{aligned}
& G_{\max }=220 K_{2} \sigma_{c}^{0.50} \\
& G_{\max }=850 \frac{(2.17-e)^{2}}{1+e} \sigma_{c}^{0.44} \\
& G_{\max }=8400 \frac{(2.17-e)^{2}}{1+e} \sigma_{c}^{0.50}
\end{aligned}
$$

In Eq. (1) and Eq. (3), $e$ is void ratio, $\sigma_{c}$ is confining pressure in $\mathrm{kPa}, G_{\max }$ in $\mathrm{kPa}$, and $K_{2}$ is defined as shear modulus number proposed by Seed and Idriss (1970). On the other hand, in Eq. (2), $e$ is void ratio while confining pressure, $\sigma_{c}$, and $G_{\max }$ unit should be in $\mathrm{kg} / \mathrm{cm}^{2} . K_{2}$ value is assumed to be 70 based from the relative density of $90 \%$ of the soil sample since there are no data available for $K_{2}$ at $D_{r}$ of $95 \%$. Meanwhile, confining pressure $\sigma_{c}$ is calculated by

$$
\sigma_{c}=\frac{\left(1+2 K_{o}\right)}{3} \gamma_{d} z
$$

where $z$ is the depth, $\gamma_{d}$ is the unit weight of soil, and $K_{o}$ is the at rest lateral earth pressure coefficient. Jaky (1944) proposed
Eq. (5), which is valid only for normally consolidated (NC) sand. It is used for determining the value of $K_{o}$.

$$
K_{o}=1-\sin \varphi
$$

The $G / G_{\max }$ versus shear strain curves from Seed and Idriss (1970), Iwasaki and Tatsuoka (1977), and Kokusho (1980) are used together with the computed $G_{\max }$ values at different confining pressures for the analysis of the centrifuge test results.

\subsection{Experimental Shear Modulus Evaluation}

During a centrifuge test, a time series of acceleration signals are recorded by available instrumentation at specific points and they can be utilized to estimate shear modulus of soil deposit in the centrifuge model. Li et al. (2013) showed that in situ acceleration time histories recorded during a real earthquake can be utilized in determining the shear modulus of soil. Brennan et al. (2005) and Conti and Viggiani (2012) presented key techniques for determining the shear modulus of soils undergoing base shaking at multiple input frequencies with the use of centrifuge data. Also, Li et al. (2013) proposed a general methodology for processing the experimental data in order to minimize the errors in the evaluation of $G$.

\subsubsection{Shear Stresses}

Using the accelerometer measurements from the centrifuge tests, shear stress can be calculated. From the original shear beam equations, Zeghal and Elgamal (1994) proposed Eq. (6) to utilize measured acceleration in determining shear stress.

$$
\tau(z)=\int_{0}^{z} \rho \ddot{u} d z
$$

Shear stress $\tau$ at any depth $z$ is defined as the integration of density $\rho$ multiplied by acceleration $\ddot{u}$. It is noted that the shear stresses are dependent on the measured acceleration profile. Accelerometers need to be buried enough to maintain good contact with the soil in order to have a reliable measured acceleration. With the presence of numbers of accelerometers, shear stresses can be obtained by using the simple Newton-Cotes formula (trapezoidal integration) for the numerical integration.

\subsubsection{Shear Strains}

To calculate shear strains from the given centrifuge acceleration signals, displacements must first be obtained by using double integration. It must be noted that acceleration data must be band-filtered prior to integration to produce velocity. Then the velocity from the acceleration data integration must be filtered again to determine the displacement $u$. Filtering is important as low frequency contents present in the velocity trace produces a 
characteristic of linearly varying displacement that changing continuously after the end of shaking (Brennan et al., 2005).

Shear strains $\gamma$ can be calculated using the equations shown below. If only two instruments are present in a given soil layer (generally the surface layer), a simple first order shear strain approximation as shown in Eq. (7) is adopted.

$$
\gamma=\frac{\left(u_{i}-u_{i+1}\right)}{\left(z_{i+1}-z_{i}\right)}
$$

On the other hand, if three instruments are stacked in a soil column at any depth $z_{i}$, a second order approximation (Eq. (8)) proposed by Zeghal and Elgamal (1994) is used.

$$
x\left(z_{i}\right)=\frac{\left[\left(u_{i+1}-u_{i}\right) \frac{\left(z_{i}-z_{i-1}\right)}{\left(z_{i+1}-z_{i}\right)}+\left(u_{i}-u_{i-1}\right) \frac{\left(z_{i+1}-z_{i}\right)}{\left(z_{i}-z_{i-1}\right)}\right]}{\left(z_{i+1}-z_{i-1}\right)}
$$

\subsubsection{Calculation of Shear Modulus}

After obtaining the shear stress and shear strain at a certain depths $z$, a plot of one against the other can now give a hysteretic loop of a soil sample. With the use of this hysteresis loop obtained from the plot, evaluation of the shear modulus is now possible. Li et al. (2013) proposed a strategy on quantifying the degradation of shear modulus with respect to shear strain. Determining the best loop to be used in the calculation of the shear modulus is not an easy task. In this paper, good loops are determined by reviewing each cycle of the filtered wave signal and picking certain cycles which resembles a sine wave signal (Fig. 8a). Since drifts are still present in the hysteresis loops as an example shown in Fig. 8b, difficulties in determining the loop trend are encountered. In addition, Kobe earthquake has an irregular signal rather than a sine signal, thus, the loops constructed by Kobe earthquake are not perfectly closed and contain another small loop inside (see Fig. 8c). Therefore, a certain time period was determined to construct one regular close loop and this time frame was applied to other time histories.

The difference in the maximum and minimum stresses and the difference in maximum and minimum strains developed in a loop are used in determining the representative moduli as shown in the following equation.

$$
G=\frac{\tau_{\max }-\tau_{\min }}{\gamma_{\max }-\gamma_{\min }}
$$

\section{Results And Discussions}

The shear stress - strain hysteresis loops at different depths in the sand model during the Test-1 event are plotted in Fig. 9.

Shear stress and strain amplitudes decrease as it propagates

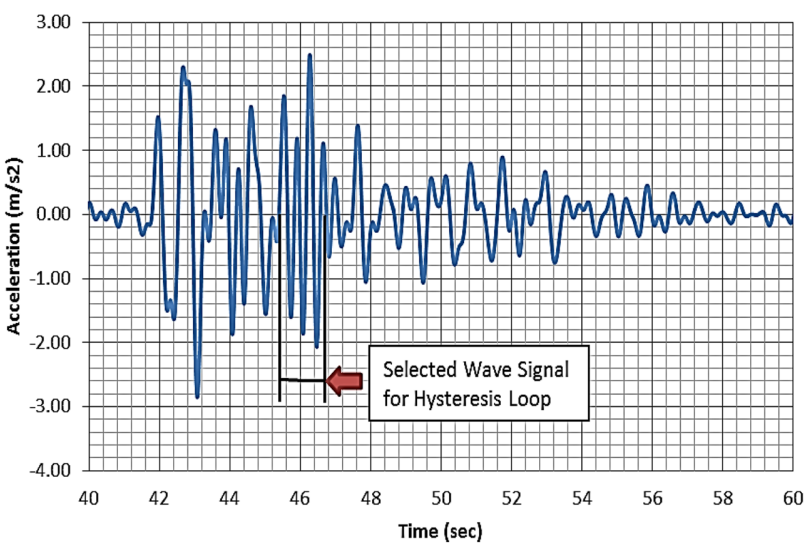

(a)

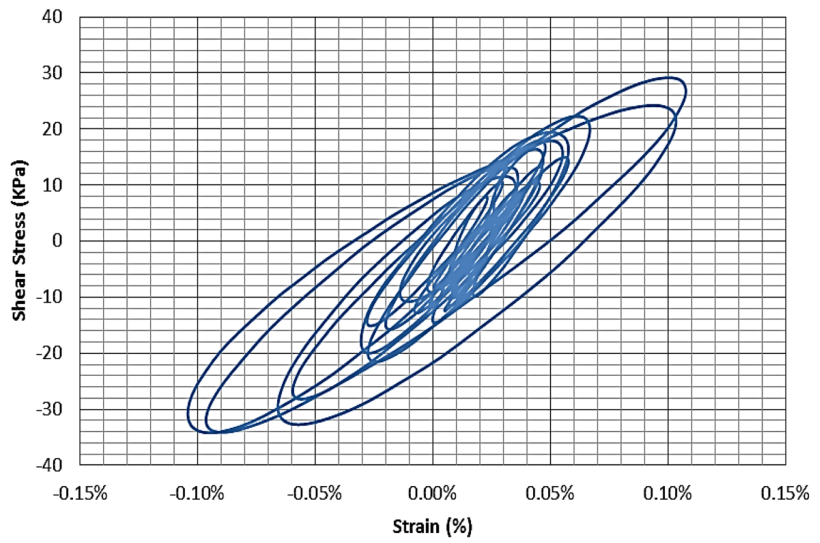

(b)

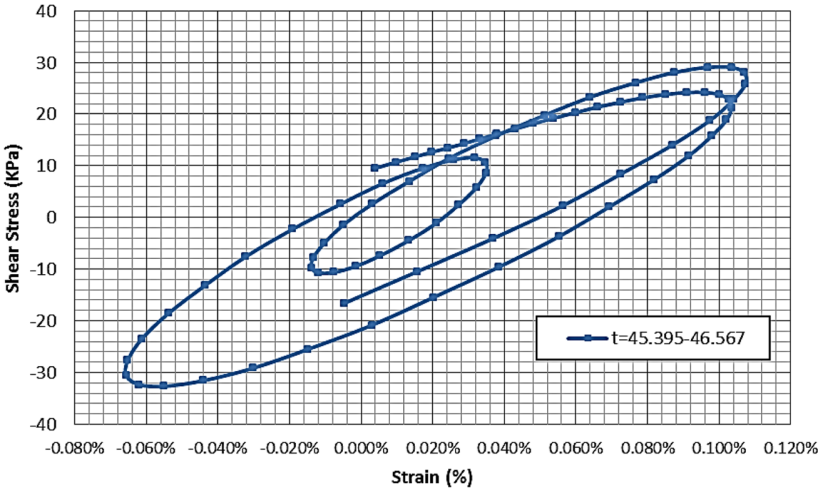

(c)

Fig. 8. (a) Filtered Signal of Kobe Earthquake, (b) Complete Hysteresis Loop of the Filtered Signal with Drift, and (c) Hysteresis Loop Using the Selected Wave Signals.

from the base (see Fig. 9c) to the surface (see Fig. 9a) and also indicate a decrease in the slope of the hysteresis loop, reflecting that the confining pressure (due to overburden pressure) is directly proportional to soil stiffness. It is noteworthy that the slope of loops becomes gentle with the increase in the amplitudes of the loops.

Fig. 10 compares the variation in the shear modulus at three different depths with the empirical curves proposed by 

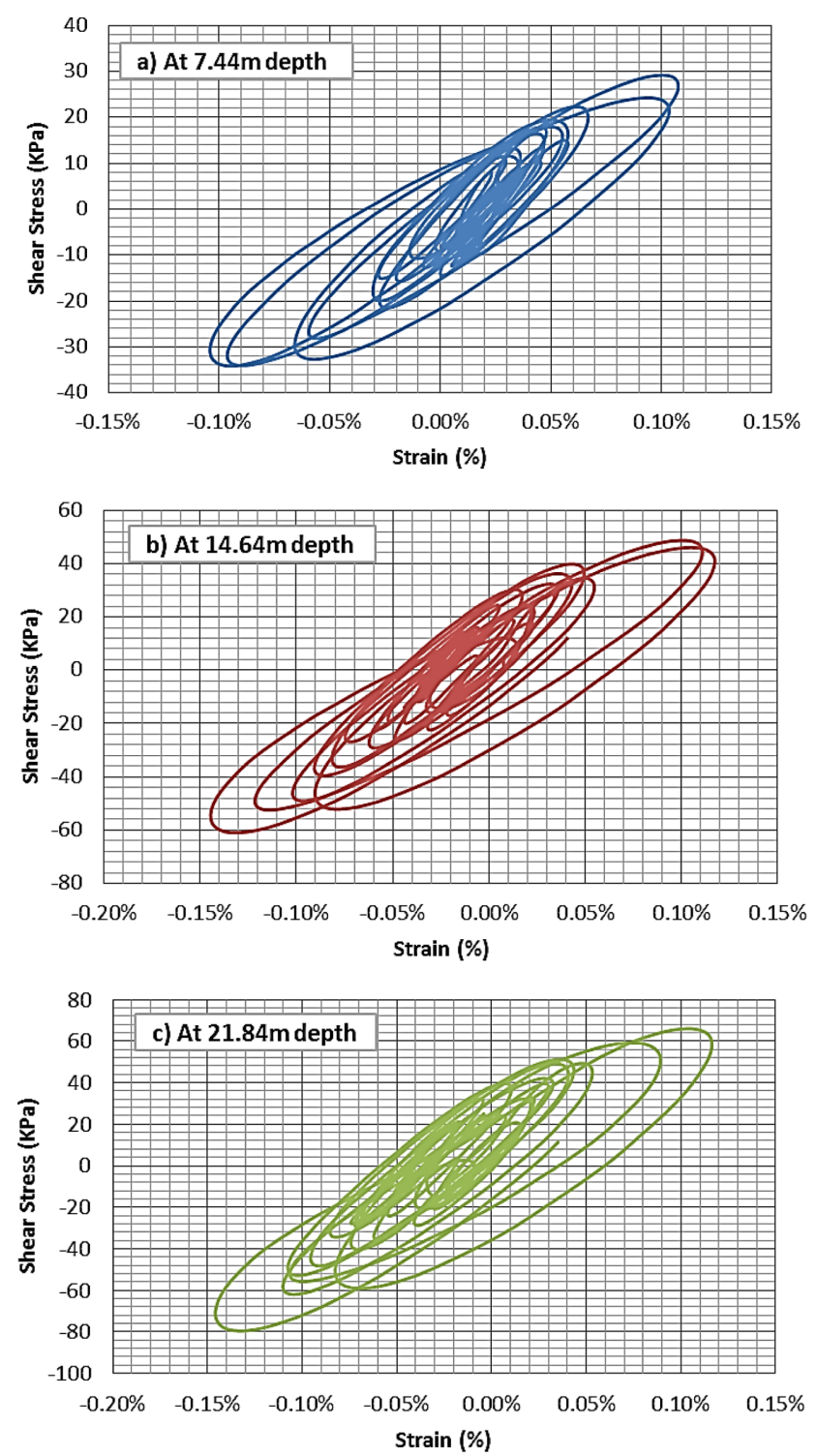

Fig. 9. Shear Stress-Shear Strain Histories at Four Different Depths during Kobe Earthquake Test-01 Event: (a) at 7.44 m, (b) at $14.64 \mathrm{~m}$, and (c) at $21.84 \mathrm{~m}$ in Prototype Scale.

Kokusho (1980) and Iwasaki and Tatsuoka (1977). The shear moduli estimated from the centrifuge tests are comparable to that of Kokusho's and Iwasaki and Tatsuoka's results for Toyoura sand. The result shows that, at a confining pressure of $65 \mathrm{kPa}$ (equivalent to $7.44 \mathrm{~m}$ of depth in prototype scale), shear modulus of $70.77 \mathrm{MPa}$ and $10.173 \mathrm{MPa}$ has a shear strain $(\gamma)$ of $0.0065 \%$ and $0.4325 \%$, respectively. For confining pressure of $129 \mathrm{kPa}$ (equivalent to $14.64 \mathrm{~m}$ of depth in prototype scale), $G$ is $103.571 \mathrm{MPa}$ and $29.629 \mathrm{MPa}$ at $\gamma$ of $0.007 \%$ and $0.27 \%$, respectively. On the other hand, $G$ is $126.92 \mathrm{MPa}$ and 51.25 $\mathrm{MPa}$ at $\gamma$ of $0.0065 \%$ and $0.16 \%$, respectively, for confining pressure of $192 \mathrm{kPa}$ (equivalent to $21.84 \mathrm{~m}$ of depth in prototype scale).

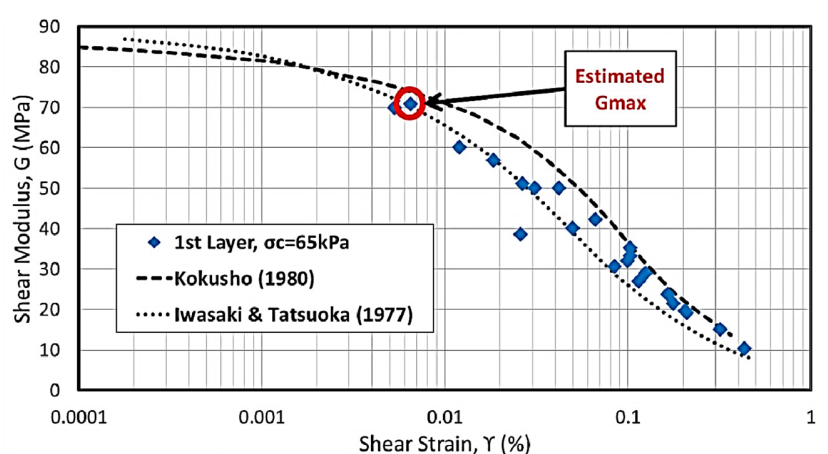

(a)

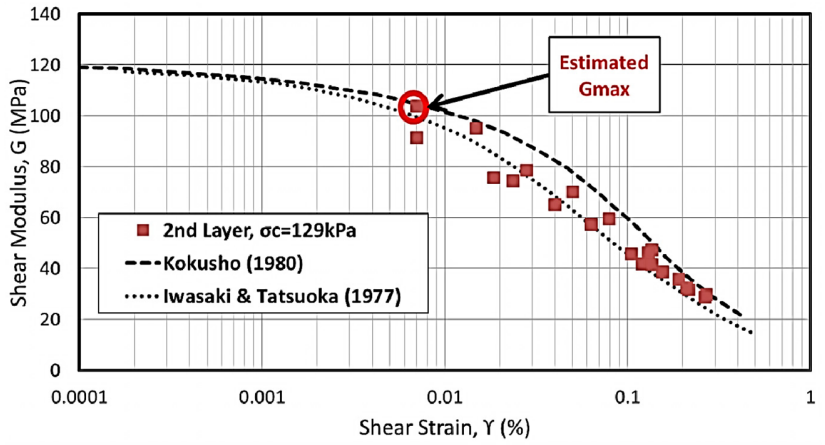

(b)

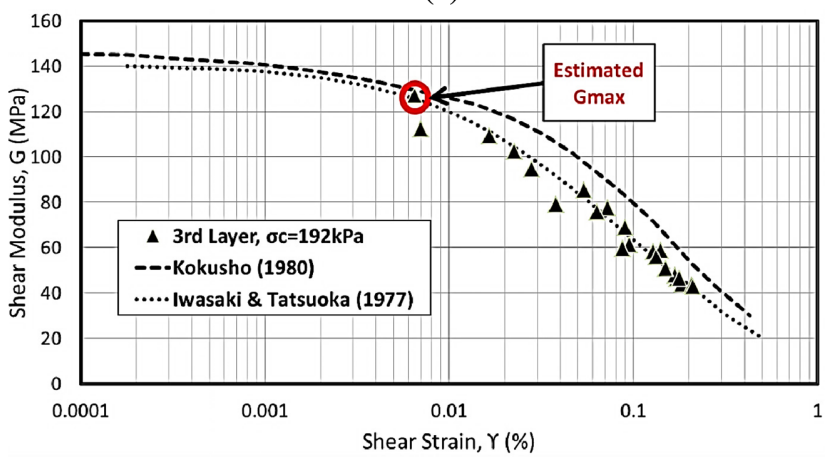

(c)

Fig. 10. Comparison of Shear Modulus vs. Shear Strain Curves of the Centrifuge Tests and Iwasaki \& Tatsuoka (1977) and Kokusho (1980) at (a) $\sigma_{c}=65 \mathrm{kPa}$, (b) $\sigma_{c}=129 \mathrm{kPa}$, and (c) $\sigma_{c}=192 \mathrm{kPa}$.

As shown in Fig. 10(a), the $G-\gamma$ points at the surface layer are adjoining or coinciding with Kokusho's curve. On the other hand, Iwasaki and Tatsuoka proposed empirical curves are close with data points at the layers 2 and 3 as shown in from Fig. 10(b) and Fig. 10(c). It is interesting to note that the shear moduli at intermediate to high strain level are comparable to the proposed curves. This comparison confirms the feasibility of the simple method evaluating non-linear shear modulus in wide high shear strain level. In addition, the result leads to a recommendation with the use of Kokusho's curve, especially, for Toyoura sand.

As presented in Fig. 10, the smallest shear strain amplitude available to estimate shear modulus in this study is around 
$0.006 \%$ to $0.007 \%$; yet this amplitude is not small enough to determine $G_{\max }$. Thus, $G_{\max }$ was determined by locating the point in the experimental $G-\gamma$ trend that has the maximum shear moduli as shown in Fig. 10. Shear modulus obtained from the stress-strain loops in the centrifuge test was normalized by $G_{\max }$ determined from the $G-\gamma$ curve at different confining pressures (circled data points in Fig. 10).

In order to obtain a representative curve for each depth from scattered data, Ramberg-Osgood model was used to obtain the $G / G_{\max }-\gamma$ fitting curves from the experiment data points at different confining pressures. The fitting was carried out using the least square method. Data points at different confining pressure together with its equivalent fitting curves are plotted in Fig. 11. Fig. 12 shows $G / G_{\max }-\gamma$ curves at different pressures obtained from the centrifuge tests and compare the $G / G_{\max }$ curves of clean sand proposed by Seed and Idriss (1977). On the other

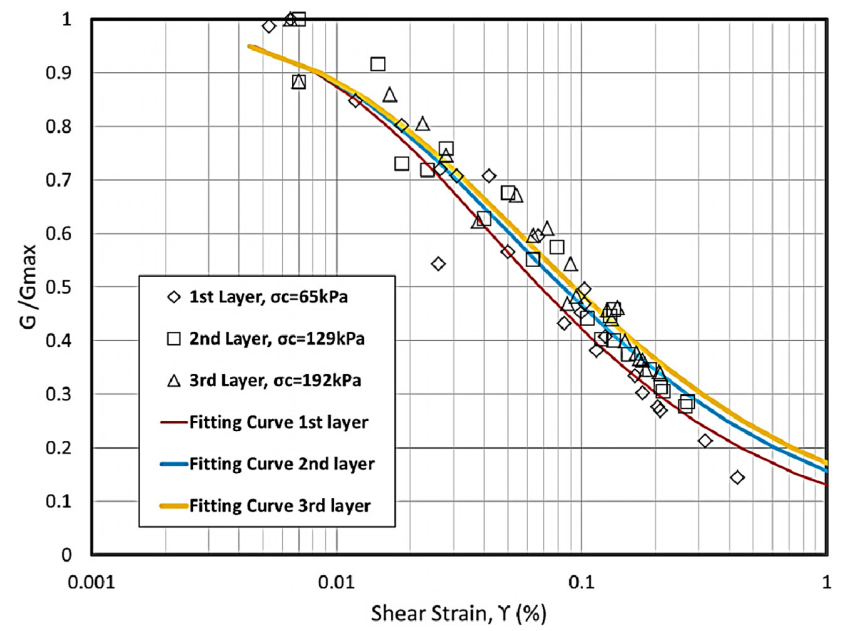

Fig. 11. Ramberg-Osgood Fitting Curves at Different Confining Pressures.

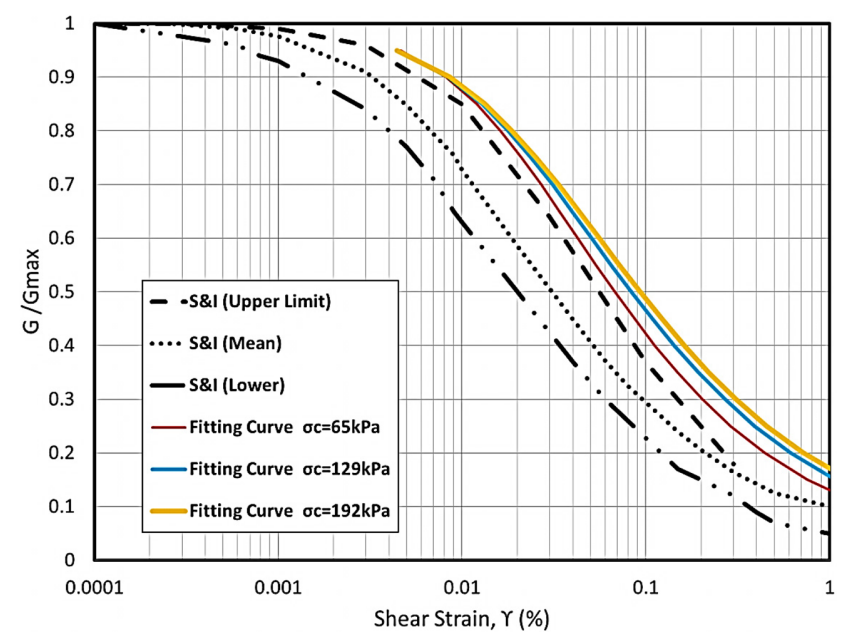

Fig. 12. Comparison of $G / G_{\max }$ Curves of the Centrifuge Tests and Seed and Idriss (1970).

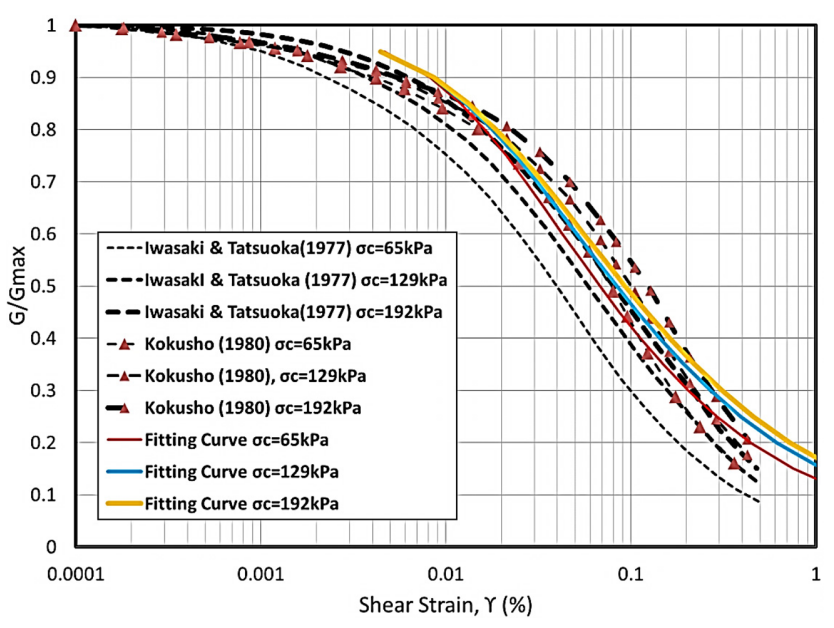

Fig. 13. Comparison of $G / G_{\max }$ Curves of the Centrifuge Tests and Iwasaki and Tatsuoka (1977) at Three Different confining Pressures: $65 \mathrm{kPa}, 129 \mathrm{kPa}$, and $192 \mathrm{kPa}$.

hand, Kokusho (1980) and Iwasaki and Tatsuoka (1977) earlier work, suggesting shear modulus degradation curves for Toyoura sand, is compared in Fig. 13. These curves must be considered as average responses since they were derived from a variety of test procedures (Conti and Vaggiani, 2012). The $G /$ $G_{\max }$ curves estimated from the centrifuge tests are approximately matched to Kokusho's work; yet they are noticeably higher than the degradation curves reported by Seed and Idriss (1970) and Iwasaki and Tatsuoka (1977).

\section{Summary and Conclusions}

In this paper, calculation methods to evaluate shear modulus were reviewed from previously published papers. A simple procedure was established using the previously proposed works. The procedure was used to obtain shear modulus of a sand deposit used for dynamic centrifuge tests. The shear modulus was successfully evaluated with the use of the shear-strain hysteresis loops derived from acceleration data at different confinement pressures. The procedure used in this study successfully captured non-linear shear modulus with shear strain and effect of confining pressure.

The estimated centrifuge data curves were compared with the empirical curves proposed by Seed and Idriss (1970), Iwasaki and Tatsuoka (1977), and Kokusho (1980). It is found that the shear modulus curves from the centrifuge tests are in reasonable agreement with Iwasaki and Tatsuoka's and Kokusho's empirical relationships proposed for Toyoura sand. It is interesting to note that the shear moduli at high strain level are comparable to the proposed curves. Also, the experimental $G / G_{\max }$ curves are noticeably higher than Seed and Idriss (1970) but are 
close to the empirical $G / G_{\max }$ proposed by Kokusho (1970). This comparison confirms the feasibility of the simple method evaluating non-linear shear modulus in wide high shear strain level. In addition, the result leads to a recommendation with the use of Kokusho's curve, especially, for Toyoura sand.

Limitations are present in this study. It is difficult to properly obtain $G_{\max }$ at small strain in this study because the response of the sand deposit induced by weak earthquake is too small to evaluate $G_{\max }$ due to noise involvement. An alternative method to measure $G_{\max }$ is recommended to be developed. This study experimental results should be also verified by laboratory tests.

\section{Acknowledgements}

This research was a part of the project titled "Development of design basis and concrete technologies for offshore wind turbine support structures/20120093" funded by the Ministry of Oceans and Fisheries, Korea.

\section{References}

Brennan, A.J. Thusyanthan N.I., and Madabhushi S.P.G. (2005) Evaluation of Shear Modulus and Damping in Dynamic Centrifuge Test. J. Geotech. Geoenviron. Eng., Vol. 131, No. 12, pp. 1488-1497.

Choo, Y.W. and Kim, D.S. (2005) Dynamic deformation characteristics of sands under various drainage conditions. Journal of the Korean Geotechnical Society, Vol. 21, No. 3, pp. 27-42.

Choo, Y.W., Lee, K.J., Yang, S.K., Kim, Y. et al. (2014) Dynamic Centrifuge Model Tests of Bucket Foundations for Offshore Wind Tower. The proc. of Earthquake Engineering Society of Korea Conference 2014, 21st, Vol. 18, pp. 141-142.

Conti, R. and Viggiani G.M.B. (2012) Evaluation of Soil Dynamic Properties in Centrifuge Tests. J. Geotech. Geoenviron. Eng. Vol. 138, No. 7, pp. 850-859.

Dobry, R. and Vucetic, M. (1987) State-of-the-art report: Dynamic Properties and Response of Soft Clay Deposits, Proc. Int. Symp. On Geotechnical Engineering of Soft Soils, 2, pp. 51-87.

Drnevich, A.M. and Richart, F.E., Jr, (1970) Dynamic Prestraining of Dry Sand, Journal of the Soils Mechanics and Foundations Division, ASCE, Vol. 96, No. 2, pp. 453-469.

Garnier, J. (2002) Properties of Soil Samples Used in Centrifuge Models, Physical Modelling in Geotechnics '02, Phillips, Guo, and Popescu, Eds., Balkema, Netherlands, pp. 5-19.

Hardin, B.O. and Drnevich, V.P. (1972b) Shear modulus and damping in soils: Measurement and parameter effects (Terzaghi Lecture). J. Soil Mech. Found. Div., Vol. 98, No. 6, pp. 603-624.

Hardin, B.O. and Richart, F.E. Jr. (1963) Elastic wave velocities in granular soils, Journal of the Soil Mechanics and Foundations Division, ASCE, Vol. 89, No. 1, pp. 33-35.

Ishihara, K. (1996) Soil behaviour in earthquake geotechnics, Oxford University Press Unc., New York, pp. 152-179.

Iwasaki, T. and Tatsuoka, F. (1977) Effects of Grain Size and Grading on Dynamic Shear Moduli of Sands, Soils and Foundations, Vol. 17, No. 3, pp. 19-35.

Jaky, J., (1944) The Coefficient of Earth Pressure at Rest, Journal of the Society of Hungarian Architects and Engineers, Budapest, Hungary, pp. 355-358.

Kim, N.R., Park, D.S., Shin, D.H. and Jung, W.S. (2014) An 800 g-tonne Geotechnical Centrifuge at K-water Institute, Korea, ICPMG 2014, Perth, Australia, pp. 175-180.

Kokusho, T. (1980) Cyclic Triaxial Test of Dynamic Soil Properties for Wide Strain Range, Soils Found., Vol. 20, No. 2, pp. 45-60.

Li, Z., Escoffier, S., and Kontronis, P. (2013) Using Centrifuge Tests Data to Identify the Dynamic Soil Propertie: Application to Fortainebleau Sand, Soil Dynamic and Earthquake Eng., Vol. 52, pp. 77-87.

Richart, F.E., Hall, J.R., and Wood, R.D. (1970) Vibrations of Soils and Foundations, Prentice Hall, Englewood Cliffs.

Seed, H.B. and Idriss, I.M. (1970) Soil Moduli and Damping Factors for Dynamic Analysis. Rep. No. EERC 70-10, University of California, Berkeley, CA.

Stokoe, K.H., II, Hwang, S.K., Lee, J.N.-K. and Andrus, R.D. (1994) Effects of Various Parameters on the Stiffness and Damping of Soils at Small to Medium Strains, In Proceedings of the First International Conference on Pre-failure Deformation Characteristics of Geomaterials, Vol. 2, pp. 785-816.

Tatsuoka, F. and Shibuya, S. (1992) Engineering Properties of Soils and Rocks From In-situ and Laboratory Tests, Key note lecture for session 1, Proc. of $9^{\text {th }}$ Asian Regional Conference on Soil Mechanics and Foundation Engineering, Vol. 2, pp. 101170.

Vucetic, M. (1994) Cyclic Threshold Shear Strains in Soils, Journal of Geotechnical Engineering, ASCE, Vol. 120, No. 12, pp. 2208-2228.

Yamashita, S., Jamiolkowski, M., and Presti, D. (2000) Stiffness Nonlinearity of Three Sands. J. Geotech. Geonviron. Eng., Vol. 126, No. 10 , pp. 929-938.

Zeghal, M. and Elgamal, A.-W. (1994) Analysis of Site Liquefaction Using Earthquake Records. J. Geotech. Eng., Vol. 120, No. 6, pp. 996-1017.

Zeng, X. and Schofield, A.N. (1996) Design and Performance of an Equivalent-shear-beam Container for Earthquake Centrifuge Modelling. Geotechnique, Vol. 46, No. 1, pp. 83-102.

\begin{tabular}{|l|l|}
\hline Received & May 14, 2014 \\
\hline Revised & May 19, 2014 \\
\hline Accepted & June 2, 2014 \\
\hline
\end{tabular}

